\title{
Komposisi Spesies Teripang (Holothuroidea) di Perairan Kampung Kapisawar Distrik Meos Manswar Kabupaten Raja Ampat
}

\section{Species Composition of Sea Cucumber (Holothuroidea) in the Kapisawar Village Meos Manswar District Raja Ampat Regency}

\author{
Tutik Handayani*, Vera Sabariah \& Ronald R. Hambuako \\ Manajemen Sumberdaya Perairan FPIK UNIPA Manokwari \\ Jl. Gunung Salju Amban Manokwari-Papua Barat 98314 \\ *Penulis untuk korespondensi, e-mail: tutiksdp2011@gmail.com
}

\begin{abstract}
Abstrak
Penelitian ini bertujuan untuk mengetahui jenis dan komposisi teripang di Perairan Kampung Kapisawar. Penelitian ini dilaksanakan selama 1 bulan yaitu pada Maret-April 2014, bertempat di perairan kampung Kapisawar Distrik Meos Mansar Kabupaten Raja Ampat Papua Barat. Metode penelitian yang digunakan adalah metode deskriptif dengan teknik observasi secara langsung menggunakan belt transect. Identifikasi spesies teripang dilakukan dengan cara pengamatan spikula. Hasil yang diperoleh dari ketiga stasiun penelitian ditemukan 10 jenis teripang yang berasal dari 3 famili 4 genus. Sepuluh jenis teripang yang ditemukan di perairan Kampung Kapisawar antara lain yaitu Holothuria scabra, $H$. leucospilota, $H$. rigida, $H$. sucosa, Bohadschia similis, B. marmorata, $B$. vitiensis, Synapta maculate, Opheodesoma grisea dan Stichopus variegatus. Komposisi teripang paling tinggi ditemukan pada stasiun I yaitu sebanyak 9 spesies yang berasal dari 3 famili dan 4 genus, stasiun II ditemukan teripang yang berasal dari 2 famili dan 3 genus dan terendah pada perairan stasiun III ditemukan 3 spesies yang berasal dari 2 famili dan 2 genus. Teripang yang ditemukan termasuk jenis yang bernilai ekonomis dengan komposisi tertinggi ditemukan di stasiun I karena habitat yang terdiri dari substrat berpasir, pasir dengan lamun, pecahan karang dan karang serta kualitas perairan, sedangkan komposisi terendah terdapat di perairan stasiun III yang agak jauh dari perkampungan.
\end{abstract}

Kata kunci: Kapisawar, komposisi jenis, Raja Ampat, spikula, teripang

\begin{abstract}
This study aimed to investigate the species and its composition of sea cucumber in the Kapisawar village of Meos Manswar District in Raja Ampat Regency. This research was conducted from March to April 2014. Descriptive method was applied directly through observations by using belt transects that consisted of three stations. Then, identification of species was done through spicula appearance of sea cucumbers. Results showed that from all research stations, 10 species of sea cucumbers were found, and these species derived from 3 families and 4 genera. The species of sea cucumbers are Holothuria scabra, $H$. leucospilota, $H$. rigida, $H$. sucosa, Bohadschia similis, B. marmorata, B. vitiensis, Synapta maculate, Opheodesoma grisea and Stichopus variegatus. The highest number of sea cucumber species was found in the station I which consisted of 9 species from 2 families and 4 genera, followed by station II ( 2 families and 3 genera), and the lowest at the station III of 3 species (2 families and 2 genera). Some of the sea cucumber found in the research station were economic importance, with the highest composition was at the station I because of its suitable habitat condition and the lowest in station III due to far from the village.
\end{abstract}

Key words: Kapisawar, sea cucumber, spesies composition, Raja Ampat, spicula

\section{Pengantar}

Kabupaten Raja Ampat merupakan Kabupaten kepulauan yang terdiri dari 610 pulau dengan luas sekitar 4,6 juta hektar. Kabupaten Raja Ampat terdiri atas 24 distrik dan 105 kampung, salah satunya adalah kampung Kapisawar. Kampung Kapisawar terletak dalam wilayah pemerintahan Distrik Meos Mansar dan merupakan dataran pulau bentuk 
berpantai landai dengan ketinggian dari permukaan air $1,5-2 \mathrm{~m}$ dan panjang garis pantai $\pm 310 \mathrm{~m}$. Ekosistem yang terdapat di kampung ini antara lain lamun, mangrove, dan terumbu karang, dengan potensi perikanan yang cukup melimpah baik dari hasil ikan (ikan tenggiri, cakalang, kerapu, kerapu) maupun non ikan (gastropoda, udang, teripang).

Teripang atau yang lebih dikenal dengan ketimun laut merupakan salah satu organisme dari filum Echinodermata kelas Holothuroidea. Teripang (Holothuroidea) dapat ditemukan atau dijumpai diseluruh perairan pantai, mulai dari daerah pasang surut yang dangkal sampai perairan yang lebih dalam untuk hidupnya, teripang lebih menyukai perairan bebas dari pencemar,dan airnya relatif tenang. Pada umumnya masing-masing jenis memiliki habitat yang spesifik misalnya, teripang putih (Holothuria scabra) banyak terdapat di perairan yang ditumbuhi lamun (sea grass), sedangkan teripang koro (Muelleria leconoro) dan teripang pasir banyak ditemukan di perairan yang lebih dalam (Martoyo et al., 2007). Habitat utama teripang adalah pada lamun dan karang. Penyebaran teripang di Indonesia sangat luas antara lain; perairan pantai Madura, JawaTimur, Bali, Sumba, Lombok, Aceh, Bengkulu, Bangka, Riau dan sekitarnya, Belitung, Kalimantan (bagian barat, timur dan selatan), Sulawesi, Maluku, Papua dan Kepulauan Seribu (Martoyo et al., 2007).

Teripang memiliki peran yang sangat penting baik secara ekonomi maupun ekologi. Secara ekonomi teripang dijadikan sebagai sumber makanan dan bahan dalam pembuatan kosmetika serta obat berbagai penyakit. Secara ekologi teripang berperan sebagai (Bioturbation) yaitu proses perubahan dari sedimen menjadi bentuk lain (feses) oleh hewan atau tumbuhan. Peran biologi teripang dialam/ habitatnya yaitu berupa pergerakan, pembenaman diri (Burrowing), maupun melalui kebiasaan makan biota. Selanjutnya dikatakan bahwa pengolahan sedimen dalam studi tentang teripang (Holothuridea), dikenal istilah sediment reworking (pengolahan sedimen) untuk menjelaskan peran biologi teripang melalui saluran pencernaan (Bonham \& Held, 1963; Bakus, 1973; Cadee, 1998; Uthicke, 1999).

Pemanfaatan teripang oleh masyarakat kampung Kapisawar adalah sebagai bahan makan, namun sebagian besar hasil tangkapan teripang banyak yang dijual kepada para tengkulak/penadah. Semakin tingginya permintaan teripang di pasaran mendorong masyarakat melakukan penangkapan secara terus menerus, sehingga dikhawatirkan dapat mengancam keberadaanya di alam. Ancaman utama terhadap keberadaan teripang di perairan adalah terjadinya tangkap lebih (over exploitation) akibat meningkatnya permintaan pasar dan penggunaan teripang sebagai bahan makanan maupun riset biomedis.

Data mengenai status perikanan teripang di Indonesia secara umum masih belum jelas, sedang penangkapan dan pemanfaatan teripang dari tahun ke tahun terus mengalami peningkatan. Ditambah lagi belum ada peraturan spesifik yang membatasi penangkapan dan perdagangan teripang dari perairan, menjadi permasalahan penting dalam upaya pengelolaan perikanan teripang di Indonesia. Salah satu upaya untuk menyelaraskan manfaat ekonomi dan manfaat ekologi maka diperlukan pengelolaan perikanan teripang secara tepat, untuk dapat mencapai tujuan tersebut diperlukan data biologi terkait jenis-jenis teripang yang terdapat di perairan kampung Kapisawar. Identifikasi jenis teripang merupakan hal mutlak yang harus dilakukan. Identifikasi dan taksonomi teripang dapat dilakukan secara morfologi (bentuk, warna, ukuran tubuh, analisis spikula) maupun secara genetik. Tujuan dari penelitian ini adalah untuk mengetahui jenis dan komposisi teripang di Perairan Kampung Kapisawar.

\section{Bahan dan Metode}

\section{Bahan}

Bahan-bahan yang digunakan antara lain sampel teripang, alkohol $70 \%$, larutan pemutih baju. Alat yang digunakan yaitu Buku Identifikasi Teripang antara lain "Tropical Pasific Invertebrates" (Collin \& Arneson, 1995), Pasific Island Sea cucumber and Beche-demer identification card (SPC,2004), "Monograph of shallow water Indo West Pacific echinoderms" (Clark \&Rowe,1971), Mikroskop binokuler merk olimpic (Pembesaran 40x10). Kamera digital merk sony DSC-W80.

\section{Metode}

Penelitian ini dilaksanakan pada bulan Maret-April 2014, bertempat di perairan kampung Kapisawar Distrik Meos Mansar Kabupaten Raja Ampat Papua Barat. Metode penelitian yang digunakan adalah metode deskriptif dengan teknik observasi secara langsung menggunakan Belt transek. Pengambilan sampel dilakukan pada tiga stasiun yakni stasiun I pada titik kordinat S $00^{\circ} 31 ; 56,2^{\prime \prime}$ E $130^{\circ} 34^{\prime} 29,4$ " tepatnya berada dibagian timur batas kampung Kapisawar, stasiun II pada titik kordinat $\mathrm{S} 00^{\circ}$ $31 ; 48,9^{\prime \prime}$ E $130^{\circ} 34^{\prime} 25,4^{\prime \prime}$ tepatnya berada di bagian barat kampung Kapisawar danstasiun III pada titik koordinat S $00^{\circ} 31 ; 45,1^{\prime \prime}$ E $130^{\circ} 34^{\prime} 21,0^{\prime \prime}$ tepatnya beradadi luar kampung Kapisawar dengan jarak \pm 200 meter (Gambar 1.). Sampel teripang yang diambil kemudian diawetkan dengan alkohol $70 \%$, selanjutnya diidentifikasi di laboratorium manajemen 
sumberdaya perairan UNIPA. Identifikasi dilakukan berdasarkan anatomi dan morfologi teripang, dengan cara mengamati bentuk, warna tubuh, bentuk serta komposisi spikula dari jaringan integumen bagian dorsal.Pengamatan bentuk dan komposisi spikula teripang dilakukan dengan cara memotong daging teripang dengan ketebalan 1-2 cm, kemudian direndam dalam larutan pemutih baju selama 5-10 menit, selanjutanya diamati dibawah mikroskop binokuler.

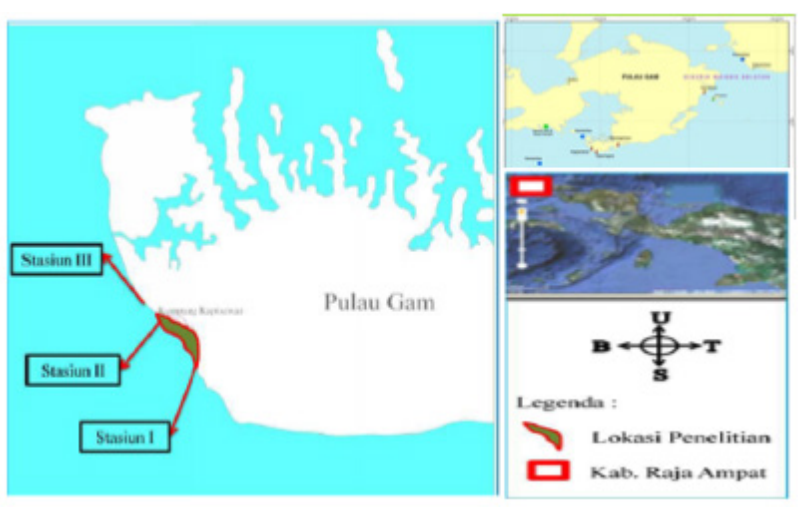

Gambar 1. Peta lokasi penelitian.

(Sumber : Hambuako, 2014)

\section{Hasil dan Pembahasan}

Berdasarkan hasil pengamatan secara morfologi dan anatomi teripang pada ketiga stasiun penelitian baik secara koleksi bebas maupun yang diketemukan didalam kuadran bahwa di perairan kampung Kapisawar diperoleh 10 jenis teripang yang berbeda. Beberapa jenis teripang yang ditemukan di dalam kuadran antara lain $H$. scabra, $H$. leucospilota, $B$. similis, B. marmorata, S. maculata dan O. grisea. Jenis teripang yang ditemukan secara koleksi bebas yaitu S. variegatus, $H$. rigida, $H$. sucosa dan $B$. vitiensis (Gambar 2)

Teripang yang ditemukan di perairan kampung Kapisawar sebagian besar merupakan jenis teripang dalam kategori ekonomis tinggi yang banyak ditangkap untuk diperdagangkan maupun dikonsumsi sendiri oleh nelayan. Kecuali jenis teripang $S$. maculata dan O. grisea yang termasuk jenis non ekonomis sehingga tidak/belum dimanfaatkan, serta dikarenakan masyarakat tidak mengetahui bahwa jenis tersebut termasuk teripang. Menurut Yusron (2007), jenis teripang yang termasuk ke dalam kategori utama adalah teripang pasir (H. scabra), teripang perut hitam $(H$. atra), teripang susuan $(H$. nobilis), teripang perut merah $(H$. edulis) dan teripang nanas ( $T$. ananas), sedangkan yang termasuk ke dalam kategori bernilai ekonomi sedang adalah teripang lotong ( $A$. lecanopra) dan teripang bilalo
(A. mauritiana) yang termasuk kedalam marga Actinopyga, jenis-jenis lainnya termasuk kedalam kategori ekonomi rendah.

Komposisi teripang paling tinggi ditemukan pada stasiun I yaitu sebanyak 9 spesies yang berasal dari 3 famili dan 4 genus, stasiun II ditemukan teripang yang berasal dari 2 famili dan 3 genus dan terendah pada perairan stasiun IIIditemukan 3 spesies yang berasal dari 2 famili dan 2 genus (Tabel 1). Persentase komposisi jenis teripang pada ketiga stasiun penelitian dapat dilihat pada Gambar 2. Persentase komposisi jenis teripang pada ketiga stasiun penelitian menunjukkan bahwa persentase tertinggi adalah 38,45 \% untuk jenis $O$. grisea dan terendah 2,2\% untuk jenis $\mathrm{B}$. marorata dan $\mathrm{H}$. Leucospilota.

Tingginya persentase teripang jenis $O$. grisea dan S.maculata dikarena kedua jenis ini merupakan teripang yang tdak ekonomis sehingga tidak ditangkap oleh masyarakat. Tingginya komposisi jenis teripang di stasiun I, diduga faktor lingkungkan seperti habitat yang terdiri dari substrat berpasir, pasir dengan lamun, pecahan karang dan karang serta kualitas perairan seperti salinitas, $\mathrm{pH}$, suhu, kecerahan yang masih stabil sehingga sangat mendukung kehidupan teripang. Hal sesuai dengan pernyataan Bakus (1973) bahwa teripang adalah organisme yang menempati substrat berpasir, bersifat deposit feeder yaitu pemakan apa saja yang terdapat di dasar perairan seperti detritus, partikel pasir, hancuran karang, diatom, filamen alga biru, alga merah, serpihan bulu babi, copepoda, telur ikan, dan beberapa mikroorganisme lain.

Pada lokasi penelitian memiliki karakteristik perairan pantai landai dengan ketinggian dari permukaan air 1,5-2 meter dengan panjang garis pantai \pm 310 meter. Di sekitar perairan kampung Kapisawar memiliki hamparan lamun Enhalus acroides yang mendominasi ketiga lokasi pengambilan sampel dan juga beberapa jenis alga lain. Stasiun I dan II berada di depan pemukiman masyarakat yang sering melakukan aktifitasnya setiap hari dan stasiun III yang berada diluar kampung Kapisawar yang mana stasiun III ini belum terlalu banyak aktifitas masyarakat terutama buangan limbah masyarakat.Pada stasiun I, II dan III memiliki kondisi keanekaragaman yang termasuk dalam kategori sedang, ini diduga karena spesies teripang pada ketiga stasiun ini mampu mentolerir kondisi lingkungan perairan pada yang memiliki tipe substrat yang cocok (pasir berlumpur, pasir halus, pasir berbatu, karang, lamun dan alga) untuk mencarimakanan dan membenamkan diri dari predator sehingga dapat mendukung pertumbuhannya. Habitat utama teripang yaitu 


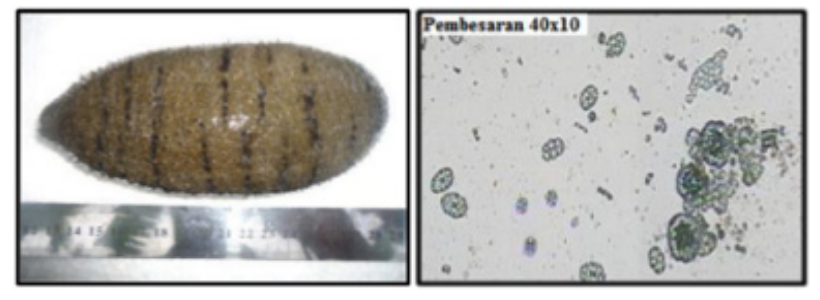

Holothuria scabra
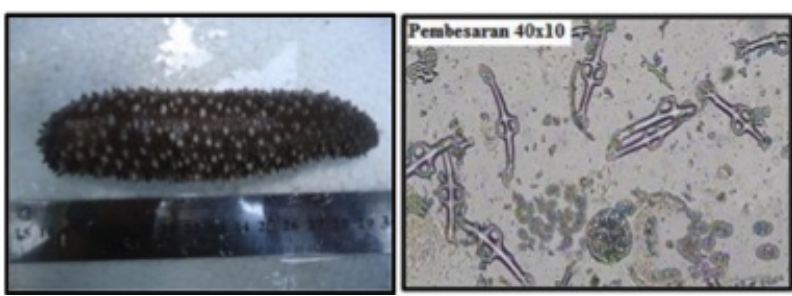

Holothuria rigida

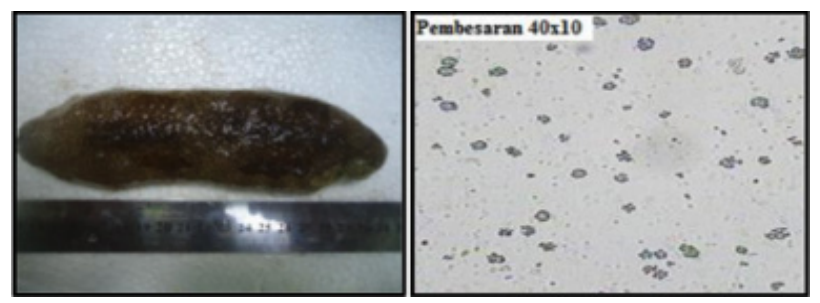

Bohadschia similis

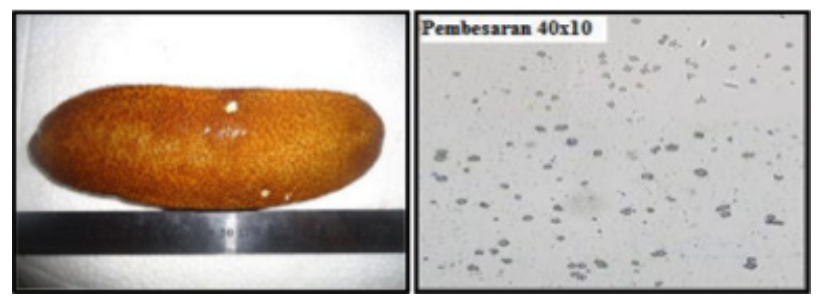

Bohadschia vitiensis



Opheodesoma grisea

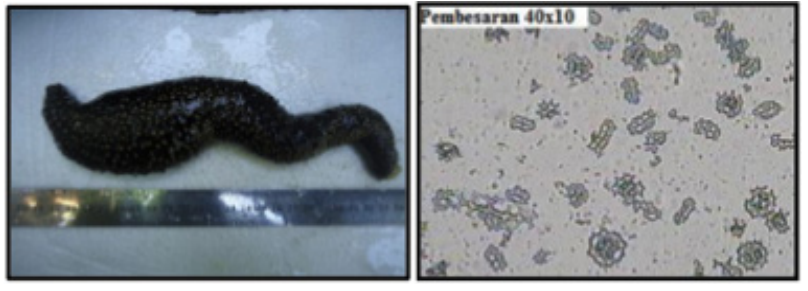

Holothuria leucospilota

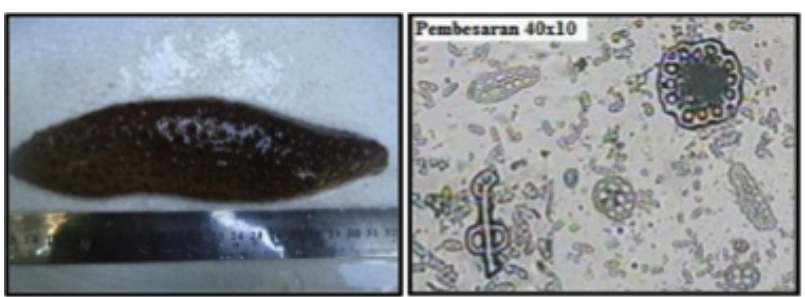

Holothuria leucospilota

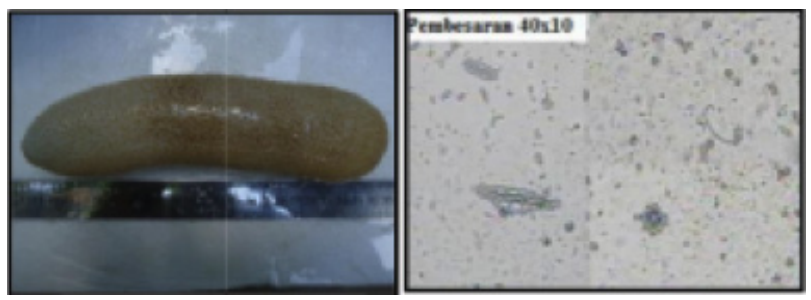

Bohadschia marmorata

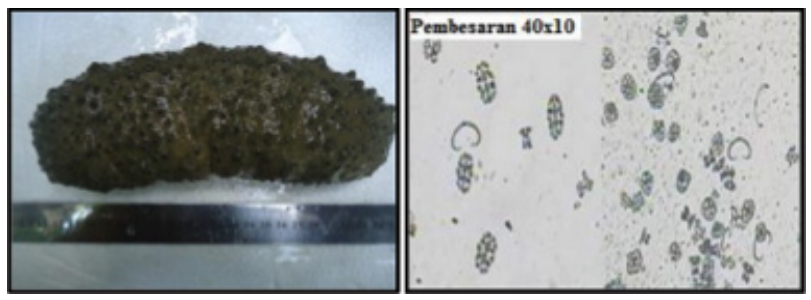

Stichopus variegatus

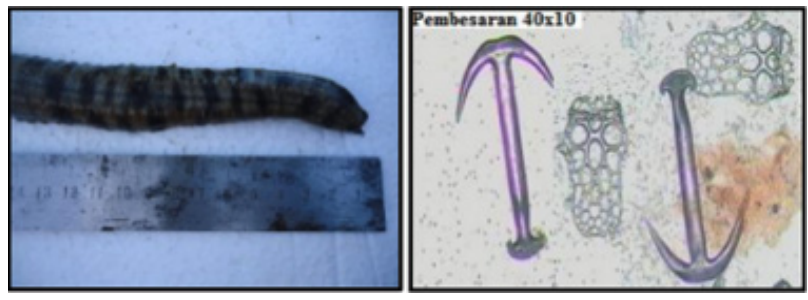

Synapta maculata

Gambar 2. Jenis teripang yang diketemukan di perairan kampung Kapisawar dan spikula masingmasing jenis teripang (Hambuako, 2014).

karang dan lamun. Habitat ini berfungsi sebagai pelindung dan perangkap makanan bagi teripang. Di daerah karang dan padang lamun merupakan habitat yang banyak banyak ditempati oleh teripang untuk melindungi diri dari sinar matahari karena hewan ini sangat peka terhadap sinar matahari (Sabariah et al., 2011).

Selanjutnya Aziz (2005) menyatakan bahwa teripang suku Holothuriidae dan Stichopodidae dapat beradaptasi dan menempati segala macam tipe dasar (substrat), seperti lumpur, lumpur pasiran, pasir, pasir lumpuran, kerikil, pantai berbatu, karang mati, pecahan karang (rubbles), dan bongkahan karang (boulders). Menurut Martoyo et al. (2007) bahwa suhu yang baik bagi pertumbuhanteripangyaitu pada kisaran suhu air antara $24-30{ }^{\circ} \mathrm{C}$, kadar garam 28-32 ppt, pH air 6,5-8,5, oksigen terlarut 4-8 ppm dan kecepatan arus $0,3-0,5 \mathrm{~m} /$ detik dan kecerahan 
Tabel 1. Komposisi jenis teripang yang ditemukan di perairan kampung Kapisawar.

\begin{tabular}{|c|c|c|c|c|}
\hline Jenis teripang & Nama lokal & Stasiun I & Stasiun II & Stasiun III \\
\hline \multicolumn{5}{|l|}{ Famili Holothuridae } \\
\hline \multicolumn{5}{|l|}{ Genus Holothuria } \\
\hline H. scabra & Pimam Kateu & + & + & - \\
\hline H. leucospilota & Pimam Kaworet & + & - & - \\
\hline H. rigida & Pimam Keru bau & + & + & - \\
\hline H. sucosa & Pimam Kawasa & - & + & - \\
\hline \multicolumn{5}{|l|}{ Famili Holothuridae } \\
\hline \multicolumn{5}{|c|}{ Genus Bohadschia } \\
\hline B. similis & Pimam manyartut & + & + & + \\
\hline B. marmorata & Pimam Lawe-lawe & + & - & - \\
\hline B. vitiensis & Pimam Lawe-lawe & + & - & - \\
\hline \multicolumn{5}{|c|}{ Family Stichopodidae } \\
\hline \multicolumn{5}{|c|}{ Genus Stichopus } \\
\hline S.variegatus & Pimam Mangkroungkre & + & - & - \\
\hline \multicolumn{5}{|l|}{ Famili Synaptidae } \\
\hline S. maculata & Paraer & + & + & + \\
\hline O. grisea & Paraer & + & + & + \\
\hline
\end{tabular}

Keterangan : + = ditemukan; - = tidak ditemukan

$50-150 \mathrm{~cm}$. Teripang umumnya lebih menyukai perairan yang jernih, dasar perairan berpasir halus atau pasir bercampur lumpur dengan tumbuhan yang dapat melindungi secara tidak langsung dari panas matahari seperti lamun dan rumput laut (Enhalus, Thalasia, Laminaria) (Aziz 1999; Hartati et al., 2002; Purwati et al.,2008). Komposisi teripang terendah ditemukan pada stasiun III yang letaknya agak jauh dari perkampungan, hal ini diduga lebih disebabkan faktor lain seperti predator alami, karena jika kita perhatikan faktor kualitas air, habitat pada stasiun ke III relatif sama dengan stasiun I dan II, begitu juga dengan keanekaragaman jenis teripang yang ditemukan pada stasiun III tidak jauh berbeda dengan staisun I dan II.

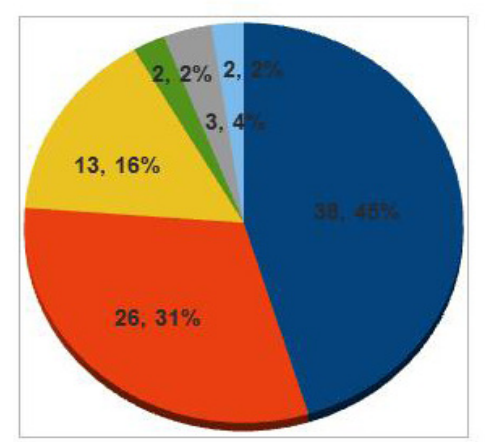

- Opheodesoma grisea

- Synapta maculata

$=$ Bohadchia similis

- Bohadchia marmorata

- Holothuria scabra

- Holothuria leucospilota

Gambar 3. Persentase komposisi jenis teripang ditiga stasiun penelitian.

\section{Kesimpulan dan Saran}

\section{Kesimpulan}

Berdasarkan penelitian ditemukan sepuluh jenis teripang di perairan kampung Kapisawar yang termasuk dalam kategori ekonomi utama dan kategori ekonomi rendah. Kesepuluh jenis teripang tersebut yaitu $H$. scabra, $H$. leucospilota, $H$. rigida, $H$. sucosa, B. similis, B. marmorata, B. vitiensis, S. maculate, O. grisea dan $S$. variegatus. Persentase komposisi tertinggi adalah $38,45 \%$ untuk jenis $\mathrm{O}$, grisea dan terendah $2,2 \%$ untuk jenis $B$. marmorata dan $H$. leucospilota.

\section{Saran}

Diperlukan penelitian lebih lanjut tentang teripang di perairan kampung Kapisawar dan Raja Ampat secara umum terkait dengan taksonomi secara genetik, aspek ekologi maupun aspek ekonominya.

\section{Ucapan Terima Kasih}

Ucapan terima kasih saya sampaikan kepada rekan rekan tim peneliti yakni Ronal R. Hambuako, S.Pi. dan juga ibu Dr.Ir. Vera Sabariah, M.Sc. atas kerja sama dan ke kompakkannya selama proses penelitian dari awal kegiatan hingga selesai. Tidak lupa juga ucapan terima kasih kami sampaikan kepada masyarakat kampung Kapisawar yang secara sukarela telah membantu kegiatan penelitian di lapangan. 


\section{Daftar Pustaka}

Aziz, A. 1987. Beberapa catatan tentang perikanan teripang di Indonesia dan kawasan Indo Pasifik Barat. J.Oseana.12: 68-78

Aziz, A. 1995. Beberapa catatan tentang teripang bangsa Aspidochirotida. J.Oseana. 20: 11-23

Aziz A. 1996. Makanan dan cara makan berbagai jenis teripang. J. Oseana. 19: 43-59

Bakus. 1973. The Biology and Ecology of Tropical Holothurians In: O. A. Jones dan R. Endean (eds), Biology and Geology of Coral Reef. Vol. II. Biology I Academic Press. New York :325-367

Clark, A.M \& F.W.E. Rowe. 1971. Monograph of shallow water Indo-West Pacific echinoderms. Trustees Brotish Museum (Natural History). London, $238 \mathrm{pp}+31 \mathrm{pls}$

Conand, C. 1990. The Fishery Resources of Pacific Island Countries.Part 2. Holothurians. Food and Agriculture Organization of the United Nasions. Roma, Italy 143 pls

Collin, P.L \& C. Arneson. 1995. Tropical Pasific Invertebrates A Field Guide to the Marine Invertebrates Occurring on Tropical Pacific Coral Reefs, Seagrass Beds and Mangroves. Coral Reef Press. California U.S.A. $305 p$

Darsono., A. Aziz \& Djamali. 1998. Kepadatan stok teripang pada beberapa lokasi di Indonesia, di dalam : Noor A, Wenno LF, Syamsuddin R, Wiadnyana NN, Budimawan, Budi P, Bustaman $S$, editor. Proseding Seminar Nasional Kelautan ke-2; 24-27 Juni 1998; Universitas Hasanudin Ujung Pandang, Indonesia. Ujung Pandang (ID)Torani Buletin ilmu dan Teknologi Kelautan :264-272

Elfidasari, D.E., N. Noriko., N. Wulandari \& A.T. Perdana. 2015. Identifikasi jenis teripang genus Holothuria asal perairan sekitar kepulauan seribu berdasarkan perbedaan morfologi. J. Al-Azhar Indonesia Seri Sains dan Teknologi 1: 140-145

Hartati, S.T., I.S. Wahyuni., Suprapto \& E. Reswati. 2002. Perikanan teripang di kepulauan seribu. JPPI Ed. Sumberdaya dan Penangkapan. 8: 55-64

Hartati, S.T., I.S. Wahyuni., Suprapto \& E. Reswati. 2002. Beberapa aspek biologi teripang di perairan kepulauan seribu. JPPI Ed. Sumberdaya dan Penangkapan. 8:113-124

Martoyo J., N. Aji \& T. Winanto. 1994. Budidaya Teripang. Penebar Swadaya. Jakarta. 69 hal
Martoyo J., N. Aji \& T. Winanto. 2007. Budidaya Teripang. Penebar Swadaya. Jakarta. 76 hal

Oedjoe, M.D.R. \& C.B. Eoh. 2015. Keanekaragaman timun laut (Echinodermata: Holothuroidea) di perairan sabu raijua, pulau sabu nusa tenggara timur. J. Ilmu dan Teknologi Kelautan Tropis. 7: $309-320$

Pralampita, W.A., I.S. Wahyuni \& S. Nuraini. 1992. Dugaan potensi teripang di gugusan pulau pari kepulauan seribu. J. Penelitian Perikanan Laut. 69: 87-92

Purwati, P., P. Widianwary \& S.A.P. Dwiono. 2008. Timun laut teluk medana, lombok barat: pola sebaran dan kelimpahan. J. IImu Kelautan Universitas Diponegoro Semarang 13: 219-226

Purwati, P \& I. Wirawati. 2011. Holothuriidae (Echinodermata, Holothuroidea, Aspidochirotida) perairan dangkal lombok barat, bagian II. Genus Actinopyga, Bohadschia, Pearsonothuria, Labidodemas. J. Oseanologi. 3:1-10

Pawson D.L \& D.J. Pawson. 2008. An Illustrated Key to The Sea Cucumbers Ofthe South Atlantic Bight. Washington DC (US) Smithsonian Institution Department of Natural Recourses Charlton South Carolina :1-37

Razek F.A., N.A. Shimy., A. Rahman \& H.A. Omar. 2006. ecological observation on the abundance distribution of holothuroids (Echinodermata: Holothuroidea) in the red sea coast, egypt. Egyptian J. Of Aquatic research. 31: 346-361

Sabariah, V., M. Tarukbua \& D. Parenden. 2009. Kondisi Habitat, Distribusi dan Kelimpahan Teripang (Holothuroidea) di Pesisir Teluk Doreri Manokwari. J. Perikanan dan Kelautan. 7: 1:8

Secreatariat of the Pacific community (SPC) Noumea. 2004. Pasific Island Sea cucumber and Beche-de-mer identification card. ACIAR and Norwood Pty, Ltd. Australia. 52p

Sukmiwati M., S. Salmah., S. Ibrahim., D. Handayani \& P. Purwati. 2012. Keragaman teripang (Holothuroidea) di perairan bagian timur pantai Natuna Kepulauan. J. Natur Indonesia. 14: 131137

Uthicke S. 1999. Sediment bioturbation and imbpact of feeding activity of Holothuria atra (Halodeima) atra and Stichopus chloronotus, two sediment feeding holothurians at lizard island, great barries reef. Bulletin of Marine Science. 64: 129-141

Wulandari, N., M. Krisanti \& D. Elfidasari. 2012. 
Keragaman teripang asal pulau pramuka kepulauan seribu. J. Unnes of Life Science Universitas Negeri Semarang. 2: 1-7
Yusron, E. 2007. Sumberdaya teripang (Holothuroidea) di perairan pulau moti-maluku utara. J. Oseanologi dan Limnologi di Indones 